\title{
Evolutionary analysis and role of invertase inhibitors in regulating sucrose metabolism in peach fruit under chilling stress
}

\author{
Xingxing Wang ${ }^{1}$, Yi Chen ${ }^{1}$, Shu Jiang ${ }^{1}$, Feng Xu${ }^{1}$, Hongfei Wang ${ }^{1}$, Yingying Wei $^{1}$, and \\ Xingfeng Shao ${ }^{1}$ \\ ${ }^{1}$ Ningbo University
}

May 5, 2020

\begin{abstract}
Sucrose metabolism, particularly the decomposition of sucrose by invertase, plays a central role in plants' response to cold stress. Invertases inhibitors (INHs) evolved with higher plants as essential regulators of sucrose metabolism. By limiting invertase activity, INHs keep cellular sugar levels elevated, which provides enhanced protection for plants under stress. As the only vacuolar invertase (VIN) gene in peaches sensitive to chilling temperatures, our results showed that PpVIN2 expression increases significantly during cold storage, while VIN activity increases more modestly. We also found that peaches transiently overexpressing PpINH1 had decreased VIN activity. The interaction of PpINH1 and PpVIN2 was shown by yeast two-hybrid, bimolecular fluorescence complementation, and in vitro, with recombinant proteins. During cold storage, trehalose treated peaches had significantly increased PpINH1 expression, decreased VIN activity, and significantly higher sucrose content than untreated fruit. As a result, treated fruit had enhanced resistance to chilling injury. Collectively, our data show that the post-translational repression of VIN activity by PpINH1 helps maintain sucrose levels in peaches during cold storage, thereby improving resistance to chilling injury.
\end{abstract}

Evolutionary analysis and role of invertase inhibitors in regulating sucrose metabolism in peach fruit under chilling stress

Xingxing Wang+, Yi Chen+, Shu Jiang, Feng Xu, Hongfei Wang, Yingying Wei*, Xingfeng Shao*

College of Food and Pharmaceutical Sciences, Ningbo University, Ningbo 315800, China

+ co-first author

* Corresponding author. E-mail address: weiyingying@nbu.edu.cn(Y. Wei); shaoxingfeng@nbu.edu.cn (X. Shao).

Tel.: +86 57487609573 ; fax: +8657487608347.

Running title: PPINH1 inhibits VIN activity in peach fruit.

\section{Abstract:}

Sucrose metabolism, particularly the decomposition of sucrose by invertase, plays a central role in plants' response to cold stress. Invertases inhibitors (INHs) evolved with higher plants as essential regulators of sucrose metabolism. By limiting invertase activity, INHs keep cellular sugar levels elevated, which provides enhanced protection for plants under stress. As the only vacuolar invertase (VIN) gene in peaches sensitive to chilling temperatures, our results showed that $P p$ VIN2 expression increases significantly during cold storage, while VIN activity increases more modestly. We also found that peaches transiently overexpressing PpINH1 had decreased VIN activity. The interaction of PpINH1 and PpVIN2 was shown by yeast twohybrid, bimolecular fluorescence complementation, and in vitro, with recombinant proteins. During cold 
storage, trehalose treated peaches had significantly increased PpINH1 expression, decreased VIN activity, and significantly higher sucrose content than untreated fruit. As a result, treated fruit had enhanced resistance to chilling injury. Collectively, our data show that the post-translational repression of VIN activity by PpINH1 helps maintain sucrose levels in peaches during cold storage, thereby improving resistance to chilling injury.

Keywords: invertase inhibitor; molecular evolution;Prunus persica ; chilling stress

\section{Introduction}

Damage from low temperature stress is responsible for significant economic losses in commercial agriculture. Sugar plays a predominant role in protecting plants from damage due to low temperatures, because it regulates osmotic pressure, stabilizes membrane structures, eliminates reactive oxygen species, and functions as a signaling molecule (Keunen et al. 2013). Peaches (Prunus persica L. Batsh), like many fruits that are sensitive to low temperatures, develop chilling injuries after storage for 1 or 2 weeks at $2-5{ }^{\circ} \mathrm{C}$ (Lurie, \& Crisosto, 2005). Sucrose, the major sugar in peach fruit, decreases after harvest, while reducing sugar content increases (Borsani et al., 2009). Sucrose decomposition and the continued demand for sugar in peaches at low temperatures affects their sensitivity to cold (Puig et al., 2015). Previously we found that sucrose degradation increases in peaches subjected to chilling stress and that maintenance of high sucrose levels improves membrane stability and resistance to cold stress (Wang et al., 2013; Yu et al., 2016).

Invertases are classified according to their $\mathrm{pH}$ optima as acid, alkaline, or neutral invertase. Acid invertase (AI) is thought to be the most important enzyme in fruit sucrose metabolism because it controls the composition of sugars and affects the response to stress (Zhang, Zhang, \& Jiang, 2013; Tauzin et al., 2014). AI are further subdivided according to subcellular localization into cell wall-bound invertases (CWIN) and vacuolar acid invertases (VIN). The latter is also known as soluble AI. Multiple invertase genes are found in most plants, and peach contains 2 VIN and 5 CWIN genes (He et al, 2018). Evolutionary analyses show that CWINs exhibit more sequence variability than VINs, and suggest that they share a common VIN ancestor (Wan, Wu, Yang, Zhou, \& Ruan, 2018).

VINs catalyze the irreversible decomposition of sucrose into fructose and glucose, thereby helping to establish and maintain cell osmotic potential and protect plants from environmental stresses (Wan et al, 2018). Generally, VINs are significantly up-regulated in plants under cold stress, but VIN activity does not increase proportionately with gene expression (Liu et al., 2013). In peach, only PpVIN2 expression is sensitive to low temperature (He et al., 2018). Although Pp VIN2 expression increases substantially at cold temperatures, VIN activity increases far less, approximately 2-fold (He et al., 2018). This result suggests that VIN activity is regulated by a post-transcriptional mechanism.

Invertase inhibitors (INHs) were first identified in the 1960s as endogenous proteins that inhibit invertase activity in potato (Solanum tuberosum ) (Schwimmer et al. , 1961). They have since been shown to interact with VINs and regulate their activity, thereby playing a vital role in sugar signaling and carbon allocation (Wan et al, 2018). INHs are members of the pectin methylesterase inhibitor-related protein family, and are classified as cell wall inhibitors (CIF) or vacuolar inhibitors (VIF) according to their subcellular location (Rausch, \& Greiner, 2004). In contrast to model plants, little is known in peaches about INHs and their physiological significance, nor has the post-translational regulation of VIN by inhibitors been examined in peach fruit.

To investigate whether peach INH (PpINH) functions as a post-translational regulator of VIN activity in fruit, five PpINHgenes were cloned and their interactions with PpVIN2 were studied using the yeast twohybrid $(\mathrm{Y} 2 \mathrm{H})$ system. Based on the result of $\mathrm{Y} 2 \mathrm{H}$ assays, the interaction between PpINH1 and PpVIN2 was further determined by biomolecular fluorescence complementation (BiFC) in tobacoo. PpINH1 function was also investigated in peach fruit using anAgrobacterium -based transient expression system. Finally, PpINH1 and PpVIN2 proteins were prepared using heterologous expression systems, and interactions between the proteins were studied in vitro . 
Trehalose is a non-reducing glucose disaccharide ( $\alpha$-D-glucopyranosyl-1,1- $\alpha \mathrm{D}$-glucopyranoside) that is synthesized during abiotic stress (Benaroudj et al. 2001; Elbein et al. 2003). Exogenous trehalose treatment has been used to enhance the cold tolerance of crops and harvested fruits (Kosar et al., 2019) and fresh-cut peppers (Ding \& Wang, 2018). Here, we treated peaches with exogenous trehalose to investigate its effect on chilling injury (CI), sucrose content, VIN activity, PpVIN2 expression, and INH gene expression. The results demonstrated that the application of exogenous trehalose decreased sucrose metabolism and CI in peach fruit subjected to cold stress.

\section{Materials and methods}

\subsection{Plant material and treatments}

Peach (Prunus persica L. Batsch.'Yulu') fruits were obtained at optimum commercial maturity (about $80 \%$ maturity, accordance to grower's recommendations) from orchards at the Fenghua Honey Peach Institute (Zhejiang, China). Fruits were selected for uniform size, homogeneous color, and absence of disease and physical damage. A total of 300 peaches were randomly divided into two groups. The treatment group was immersed in a trehalose solution, $1 \%(\mathrm{~m} / \mathrm{v})$, for 10 minutes, and the control group was immersed in the same volume of distilled water. Fruits were then air-dried and stored at $5{ }^{\circ} \mathrm{C}$ under $92-95 \%$ relative humidity. Sampling was performed after $0,7,14,21$, and 28 days of refrigeration. Mesocarp slices (about $1 \mathrm{~cm}$ thick) were frozen in liquid nitrogen and stored at $-80{ }^{\circ} \mathrm{C}$. Three replicates, consisting of 10 fruit per replicate, were taken at each time point for biochemical and molecular analyses.

\subsection{Bioinformatic and evolutionary analyses}

To investigate changes in INH genes during plant evolution, the PpINH1 protein sequence was used to query the One Thousand Plant Transcriptomes database (https://db.cngb.org/onekp/) using BLASTP. Database sequences that aligned with expectation values (E-values) less than $10^{-10}$ were set aside as candidates. Variations in INH gene copy number during plant evolution were investigated using the Phytozome database (https://phytozome.jgi.doe.gov/pz/portal.html). In this analysis, PpINH1 was aligned to sequences using BLASTP with the same significance criterion (E-value $<10^{-10}$. To analyze INH gene conservation, the nucleic acid sequences of candidate INH genes from Amborella trichopoda, Prunus persica, Brasica rapa, Medicago truncatula, and Solanum lycopersicum were downloaded from Phytozome. Finally, 19 nucleic acid sequences were aligned with ClustalW, and phylogenic trees were constructed using the Maximum Likelihood method in MEGA 7.0 with 1000 bootstrap replicates.

Isoelectric points and molecular masses were predicted using Compute $\mathrm{pI} / \mathrm{Mw}$ (https://web.expasy.org/compute_pi/). Signal peptides and locations of putative signal peptide cleavage sites were predicted using ProP 1.0 (http://www.cbs.dtu.dk/services/ProP/). The amino acid sequences of PpINH1 and PpVIN2 were compared against entries in the Protein Data Bank (http://www.rcsb.org/) using BLASTP. The crystal structure of a cell wall invertase inhibitor from tobacco (PDB-ID 1RJ1) (Hothorn et al. 2004) with $40 \%$ sequence identity was used as a model to predict the three-dimensional structure of PpINH1. The predicted three-dimensional structure of PpVIN2 is based on the crystal structure of a 6-SST/6-SFT from Pachysandra terminalis (PDB-ID 3UGF) (Lammens et al., 2012) with 67\% sequence identity. The resulting PDB file was analyzed using PyMOL (http://www.pymol.org).

\subsection{Y2H Assay}

Y2H was performed using the Matchmaker@ Gold Yeast Two-Hybrid System (Clontech, USA), according to the manufacturer's protocol. To generate a vector for Y2H analysis, full-length cDNAs of Pp VIN2 (GenBank Accession No. XM_007210252) and PpINHs (GenBank Accession Nos. XM_007208838, XM_007223513,XM_007209598,XM_007223389, and XM_007217302) were cloned into pGBKT7 (BD) and pGADT7 (AD) vectors, respectively. PpVIN2 was inserted at the BamHI-PstI restriction sites of pGBKT7, yielding BD-PpVIN2 . Each $P p I N H$ was inserted at the BamHI-XhoI restriction sites pGADT7, yielding five AD-PpINHs . Primers are shown in Table $\mathbf{S 1}$. The invertase and inhibitor plasmids were co-transformed into the yeast strain Y2H Gold, according to the manufacturer's instructions (Clontech, USA), including the recommended tests 
for autoactivation and toxicity. Transformants were plated onto the synthetic dropout nutrient media SD-LT (SD/-Leu/-Trp) containing X- $\alpha$-Gal, and SD-LTHA (SD/-Leu/-Trp/-His/-Ade). pGADT7-T, pGBKT7-53, and pGBKT7-Lam were also co-transformed and analyzed separately as controls.

\subsection{Subcellular localization}

To analyze the subcellular location of proteins in vivo, full-length copies of PpVIN2and PpINH1 were cloned and inserted into pCAM35s-GFP plasmids at the KpnI-XbaI and BamHI-KpnI sites, respectively, generating $P p$ VIN2 -pCAM35s-GFP and PpINH1 -pCAM35s-GFP fusion vectors. The constructs Pp VIN2 -pCAM35s-GFP, PpINH1 -pCAM35s-GFP, and the empty vector pCAM35s-GFP were transformed into Agrobacteriumstrain GV3101, then injected into the leaf epidermis of Nicotiana benthamiana . After incubation for two days, the inoculated leaves were examined by fluorescence microscopy using a laser scanning confocal microscope (FV10-ASW, OLYMPUS, Japan).

\subsection{Bimolecular fluorescence complementation (BiFC)}

For YFP fusion vector construction, the full length PpVIN2 coding sequence (CDS) was synthesized and cloned into pSPYNE-35s at the XbaI-BamHI restriction sites. Similarly, the PpINH1 CDS was synthesized and cloned into pSPYCE-35s at the XbaI-BamHI sites. The resulting plasmids were PpVIN2 -N-YFP $(P p$ VIN2 - YN) and PpINH1 -C-YFP (PpINH1 - YC). Constructions were transiently expressed in tobacco leaves as described by Glass et al. (2015). Fluorescence signals and bright field images were obtained with a confocal microscope (OLYMPUS, Japan). YFP and GFP emissions were measured at the excitation wavelengths of $514 \mathrm{~nm}$ and $498 \mathrm{~nm}$, respectively.

\subsection{Agrobacterium-based transient transformation}

Assays for transient expression in peach fruit were conducted following protocols described by Zhang et al. (2015) and Li et al. (2017), with minor modifications. To generate the overexpression construct, thePpINH1 CDS was excised from the BiFC fusion vector and ligated into a pBI121 vector, generating pBI121-PpINH1 , which was subsequently transformed into Agrobacterium tumefaciensGV3101. The pBI121 vector was used as a negative control.

A. tumefaciens transformants ( $1 \mathrm{ml}$ of $3 \mathrm{OD}_{600}$ units) were injected into mature green 'Yulu' peaches. Peaches were sampled 24, 36, 48, and $72 \mathrm{~h}$ after inoculation. The area of infection was a radius of about 1 $\mathrm{cm}$ around the injection site. At each time point fruits were cut into $1 \mathrm{~cm}^{2}$ slices approximately 1-2 mm thick. Expression of the GUS reporter plasmid (co-transformed with PpINH1) was assayed using a histochemical assay (RealTimes, Beijing, China). For VIN activity andPpINH1 expression assays, peels were removed with a scalpel, and the infected tissue was cut into pieces of about $0.5 \mathrm{~g}$. Pieces were flash frozen in liquid nitrogen and stored at $-80{ }^{\circ} \mathrm{C}$.

\subsection{Quantitative real time PCR (qRT-PCR) analysis}

RNA isolation and cDNA synthesis were performed according to He et al. (2018). The primers used for qRT-PCR are shown in Table S1 . Translation elongation factor 2 (TEF2, JQ732180.1) was chosen as a reference gene (Wang et al., 2013). Other experimental methods related to qRT-PCR were as described by He et al. (2018).

\subsection{VIN activity assay}

VIN was assayed following the method of Schaffer et al. (1989), with modifications. Frozen samples of mesocarp $(1 \mathrm{~g})$ were homogenized on ice in $5 \mathrm{~mL}$ of extraction buffer containing $100 \mathrm{mM}$ sodium phosphate buffer ( $\mathrm{pH} 7.5), 5 \mathrm{mM} \mathrm{MgCl} 2,2.5 \mathrm{mM}$ dithiothreitol, $0.1 \%$ Tritonx-100 (v/v), and $2 \%$ polyvinypolypyrrolidone $(\mathrm{PVPP}, \mathrm{m} / \mathrm{v})$. The homogenates were centrifuged at $12,000 \times \mathrm{g}$ for $20 \mathrm{~min}$ at $4{ }^{\circ} \mathrm{C}$. Supernatants were dialyzed in $0.1 \times$ extraction buffer (without PVPP) to remove soluble sugar. VIN activity was assayed using the protocol described above. One unit of VIN activity was defined as the amount of enzyme required to produce $1 \mu \mathrm{mol}$ glucose per hour, expressed as U/g fresh weight. 


\subsection{Recombinant protein expression and purification}

To analyze the function of PpINH1 protein in vitro , the PpINH1 CDS was cloned into pET-32a at the KpnIHindIII sites, and expressed in E. coli strain BL21 (DE3) (Beijing ComWin Biotech, China) to generate a His-fusion protein. Cells were cultured in LB medium containing $100 \mu \mathrm{g} \mathrm{mL}-1$ ampicillin at $15{ }^{\circ} \mathrm{C}$ for $16 \mathrm{~h}$, with shaking at $200 \mathrm{rpm}$. Expression of the recombinant protein was induced with $1.0 \mathrm{mM}$ IPTG when cells reached a density 0.6 to $0.8\left(\mathrm{OD}_{600}\right)$. The cell pellet from a $300 \mu \mathrm{L}$ culture was lysed by sonication for 10 min in $200 \mu \mathrm{L}$ lysis buffer ( $50 \mathrm{mM}$ Tris, $150 \mathrm{mM} \mathrm{NaCl}, 5 \%$ glycerol $\mathrm{pH}$ 8.0). The lysate was then centrifuged at 15,000 rpm for 10 minutes, the supernatant was collected, and the PpINH1protein was purified using a Ni column.

For preparation of recombinant PpVIN2, the PpVIN2 CDS was cloned directly into a pPICZ $\alpha \mathrm{A}$ vector at the XhoI-NotI sites. Pichia pastoris strain X-33 was then transformed with $10 \mu \mathrm{g}$ of the linearized construct. For small-scale evaluation of protein expression, four transformant colonies were used to inoculate buffered glycerol-complex medium (BMGY). Cells were cultured to an $\mathrm{OD}_{600}$ of 3.0, pelleted by centrifugation, and re-suspended in BMGY at $28{ }^{\circ} \mathrm{C}\left(\mathrm{OD}_{600}\right.$ was adjusted to 1.0). Pure methanol was added to a final concentration of $1 \%$ volume every 24 hours for 4 days. After low-speed centrifugation, the supernatant was collected and analyzed by SDS-PAGE and western blot. Protein was purified from the culture supernatants using a Ni column.

The concentrations of the purified proteins were determined using a Micro-Bradford protein assay with bull serum albumin (Thermo Fisher, USA) as a standard. For western blot analysis, purified proteins were fractionated on a $12 \%$ SDS-PAGE gel and electrotransferred to an Immobilon-P polyvinylidene difluoride membrane (Millipore). Mouse-anti-His mAb (GenScript, Nanjing, China) was used as the primary antibody. Proteins were also displayed on a Coomassie Blue-stained $12 \%$ SDS-PAGE gel, and then protein purity was estimated by densitometric analysis.

\subsection{Recombinant protein inhibition assay in vitro}

The VIN activity of recombinant PpVIN2 was assayed as described in Section 2.8, and expressed as U/mg protein. Inhibitory effects were determined at different $\mathrm{pH}$ levels and temperatures by measuring the VIN activity of PpVIN2 in the presence of PpINH1. PpVIN2 plus double distilled water served as control. The inhibition rate was calculated by the following formula: Inhibition rate $=\left[\left(\mathrm{PpVIN} 2+\mathrm{ddH}_{2} \mathrm{O}\right)-(\mathrm{PpVIN} 2+\right.$ PpINH1)]/ $\left(\mathrm{PpVIN} 2+\mathrm{ddH}_{2} \mathrm{O}\right)$, where each term refers to VIN activity measured in the presence (+PpINH1) or absence $\left(+\mathrm{ddH}_{2} \mathrm{O}\right)$ of inhibitor.

The mixture was incubated at $37^{\circ} \mathrm{C}$ for 30 minutes in assay buffers at $\mathrm{pH} 3.2,3.6,4.0,4.4,4.8,5.2,5.6$, and 6.0. Sucrose was then added and enzyme activity was measured. These reactions were repeated at $25^{\circ} \mathrm{C}, 30$ ${ }^{\circ} \mathrm{C}, 35{ }^{\circ} \mathrm{C}, 40{ }^{\circ} \mathrm{C}, 45{ }^{\circ} \mathrm{C}, 50{ }^{\circ} \mathrm{C}$, and $55{ }^{\circ} \mathrm{C}$.

\subsection{Determination of CI Index}

Internal browning (IB) is a characteristic symptom of CI in peach fruit. IB was visually estimated after cutting along the axial diameter of 10 fruits per replicate. The estimates were in turn used to calculate the CI index (Wang et al., 2013). CI severity scores range from 0 to $4: 0=$ No IB observed, $1=$ Mild, $2=$ Moderate, $3=$ Moderately Severe, $4=$ Severe. The CI index was calculated using the formula: CI index $=$ $[(\mathrm{CI}$ score $) \times($ number of fruits with this CI score $)] /(4 \times$ total number of fruits in each treatment $)$.

\subsection{Determination of sucrose content}

Sucrose content was measured using the method of Shao et al. (2012). Briefly, $5 \mathrm{~g}$ of frozen peach tissue was finely ground in a mixture of $0.5 \mathrm{~mL}$ of solution I $(5.48 \%(\mathrm{~m} / \mathrm{v})$ zinc acetate:glacial acetic acid (97:3)) and $0.5 \mathrm{~mL}$ of solution II (potassium ferrocyanide $2.65 \%(\mathrm{~m} / \mathrm{v})$ ). The resulting homogenate was diluted with deionized water to $25 \mathrm{~mL}$ and then passed through a $0.22 \mu \mathrm{m}$ membrane filter. The sucrose content in a 20 $\mu \mathrm{L}$ aliquot of the filtrate was measured using an HPLC system (model 2695, Waters, USA), equipped with an X BrigeTM amide column (3.5mm, $4.6250 \mathrm{~mm}$, USA,) and a refractive index detector (model 2414) Waters). 
The mobile phase composition was acetonitrile/water $(80: 20 \mathrm{v} / \mathrm{v})$, the total flow rate was $1 \mathrm{~mL} / \mathrm{min}$, and the column temperature was 35 .

\subsection{Statistical analysis}

A completely randomized design was used in the experiments. Statistical analyses were performed using SAS (version 8.2, SAS Institute, Cary, NC, USA). qRT-PCR results were analyzed using the $2^{-\Delta \Delta^{\prime \prime} \tau}$ method. Figures were prepared using OriginPro 9.0 (Microcal Software Inc., Northampton, MA, USA) and GraphPad Prism 5.0 (GraphPad Software, San Diego, CA, USA). Differences between means were evaluated with Student's $t$-test.

\section{Results}

\subsection{Analysis of INH protein evolution}

To analyze the evolution of INH in green plants, the PpINH1 protein sequence was used to conduct a BLASTP search for similar proteins in the One Thousand Plant Transcriptomes database $\left(\mathrm{E}\right.$-value $\left.<10^{-10}\right)$. More than 2000 target sequences were identified in this initial step, and 100 green plant species were selected to examine INH evolution (Figure 1a ). INH was found only in the flowering plants, including conifers, monocots, and eudicots. To analyze the evolution of INH in more detail among angiosperms, we used BLASTP to query the Phytozome 12.1 database to define a smaller number of representative flowering plant species and then counted the number of INH genes in each one (Figure 1b ). It is interesting to note that no INHs were detected in Amborella trichopoda, which is the common ancestor of living angiosperms. Variations in the number of INH genes are also observed, presumably reflecting gene duplication and loss events that have occurred during speciation, and there is a clear difference between dicots and monocots (Figure 1b ). Analysis of $I N H$ genes at the nucleic acid level shows that the first of 4 conserved cysteine sites are encoded as "TGC" in all species. However, the other conserved cysteine codons are more heterogeneous (Figure 1c).

\subsection{Promoter analysis of PpINHs}

VIN regulates sucrose metabolism in conjunction with INH interaction proteins to enable plants to resist cold stress. To determine whether $P p I N H$ gene expression is sensitive to low temperature, $P p I N H$ promoters (defined as regions $3000 \mathrm{bp}$ in length directly upstream from $P p I N H$ coding sequences) were examined in the peach genome. CBF/DREB (C-repeat binding factor/dehydration responsive element) binding sites occur within each PpINH promoter(Figure 2). The CBF/DREB protein binds specifically to G(TG)CGG cis-elements involved in regulating plant responses to drought, low temperature, and stress. These results support the hypothesis that INH proteins act as key regulators in flowering plants to mediate the response to cold stress, especially in dicots.

\subsection{PpINH1 interacts with PpVIN2 in Y2H system}

Using PpVIN2 as "bait", each inhibitor protein ("prey") was tested for its ability to interact with PpVIN2 in the $\mathrm{Y} 2 \mathrm{H}$ system. Briefly, a positive result occurs when the bait and prey proteins interact to bring a DNA-binding domain (BD) and activating domain (AD) into proximity, thereby activating the transcription of reporter genes. This enables the yeast host to grow on plates that lack four amino acids, exhibit strong resistance to AbA, and generate blue colonies. Only PpINH1 detectably interacted with PpVIN2 (Figure 3a ). In control experiments (data not shown), yeast cells containing either BD-Pp VIN2 or AD-PpINH1 exhibited no self-activation or cell toxicity.

\subsection{BiFC assay shows colocalization of PpINH1 andPpVIN2 in tobacco cells}

PpINH1 is located at the cell membrane, in the cytoplasm, and in the nucleus, while PpVIN2 is located in the cell membrane and cytoplasm (Figure $\mathbf{3 b}$ ). When the genes are co-expressed in tobacco cells in a BiFC assay, PpINH1 and PpVIN2 co-localize (Figure 3c ). No appreciable fluorescence was observed when PpINH1 -YC was co-expressed with YN, when PpVIN2 -YN was co-expressed with YC, or when YC was co-expressed with YN. These results support the hypothesis that PpINH1 interacts with PpVIN2 in vivo . 


\subsection{Transient overexpression of PpINH1 in peach fruit inhibits VIN activity}

A pBI121-PpINH1 overexpression construct was introduced into peach fruit via Agrobacterium tumefaciens -mediated injection (Figure 4a, b ). As shown in Figure 4c , GUS staining shows that pBI121-PpINH1 was successfully transferred into peach fruit and is expressed. Compared with the control, expression of PpINH1 increased 47-fold, 29-fold, 11-fold, and 27-fold at 24, 36, 48, and 72h after injection, respectively (Figure 4d ).

VIN activity in peach fruit overexpressing PpINH1 decreased over the first $36 \mathrm{~h}$ after injection, then recovered almost to initial levels over the remaining $48 \mathrm{~h}$, although VIN activity remained significantly below that of controls at each time point. VIN activity in control peach fruit (injected with Agrobacterium tumefaciens containing the empty pBI121 vector), increased throughout the $72 \mathrm{~h}$ experiment (Figure 4e ).

\subsection{Expression of PpINH1 and PpVIN2 recombinant proteinsin vitro}

The 438 bp PpINH1 gene encodes a protein of 145 amino acids with a theoretical molecular mass of $15.06 \mathrm{kDa}$ and a predicted isoelectric point of 4.34. PpINH1 is not predicted to contain a signal peptide (Figure S1a ) or a transmembrane region (Figure S2a ). The PpINH1 cDNA was cloned into pET-32a and expressed as an N-terminal His-tagged protein in E. coli BL21 (DE3). After induction conditions were optimized (data not shown), expression was induced at $15{ }^{\circ} \mathrm{C}$ for $16 \mathrm{~h}$ and the protein was recovered in the supernatant (Figure 5a, b ). The yield was about $17.7 \mathrm{mg}$ per liter of culture.

The PpVIN2 CDS is 2061 nucleotides in length and encodes a protein of 686 amino acids, with a predicted molecular mass of $76.49 \mathrm{kDa}$ and an isoelectric point of 6.45. PpVIN2 is not predicted to contain a signal peptide (Figure S1b ). The C-terminus contains a potential transmembrane region (Figure S2b ). The molecular weight of the protein after removal of the transmembrane domain is $64 \mathrm{kDa}$. The addition of the His-tag results in a $73.1 \mathrm{kDa}$ fusion protein (Figure 5e, f ). To conduct biochemical and molecular studies, $P p$ VIN2 was expressed in Pichia pastoris using the pPICZ $\alpha$ A vector. After expression was induced with methanol, the recombinant protein was purified from the supernatant, with a yield of about $2.77 \mathrm{mg}$ per liter of culture. Samples of purified PpINH1-5 $\times$ His $(32.4 \mathrm{kDa})$ and PpVIN2-5 $\times$ His $(73.1 \mathrm{kDa})$ are displayed on polyacrylamide gels inFigure $\mathbf{5 c}, \mathrm{d}$ and Figure $\mathbf{5 g}, \mathbf{h}$, respectively.

\subsection{PpINH1 inhibition of PpVIN2 is affected by $\mathrm{pH}$ and temperature}

As shown in Figure 5i , PpINH1 inhibition of PpVIN2 occurs over a $\mathrm{pH}$ range from 3.2 to 6.0, with maximum inhibition at $\mathrm{pH} 4.4$ (Figure $\mathbf{5 j}$ ), close to the optimum $\mathrm{pH}$ for VIN activity ( $\mathrm{pH} 4.5$ ). Inhibition gradually weakens at $\mathrm{pH}$ values in excess of 5.2 .

PpINH1 inhibition of PpVIN2 activity was also measured at temperatures ranging from $25{ }^{\circ} \mathrm{C}$ to $55{ }^{\circ} \mathrm{C}$ (Figure 5k ). As shown inFigure 5l, inhibition was greatest at $35{ }^{\circ} \mathrm{C}($ Figure 5l ) and weakened rapidly as temperatures increased. These results demonstrate that PpINH1 is a potent inhibitor of PpVIN2 activity, and that inhibition varies with $\mathrm{pH}$ and temperature in vitro .

3.8 Postharvest trehalose treatment up-regulates PpINH1 and increases chilling resistance of peach fruit

CI in peaches occurred after two weeks of storage at $5{ }^{\circ} \mathrm{C}$. Visible flesh browning was observed on day 21 of storage, and at day 28 severe CI was observed. In contrast, peaches treated with trehalose did not exhibit substantial CI after 21 or 28 days of storage (Figure $\mathbf{6 a}, \mathbf{6 b}$ ). Sucrose content in trehalose-treated fruit was significantly higher than in untreated control fruit throughout the 28-day storage period (Figure 6c ). In control fruit, VIN activity increased nearly 2-fold during 28 days of cold storage (Figure 6d ), whilePp VIN2 expression increased more than 500 -fold by the $21^{\text {st }}$ day of storage (Figure 6e ). In trehalose-treated fruit, VIN activity also increased during storage, but remained lower than in the control fruit. Pp VIN2 expression also increased with storage time but was significantly lower than in control fruit on days 21 and 28 . Expression of PpINH1 in control fruit decreased significantly during storage, as did expression in trehalose-treated fruit, 
but PpINH1 expression in treated peaches remained significantly higher throughout cold storage (Figure 6f ).

\section{Discussion}

\subsection{PpINHs are cold-responsive regulators that have evolved with flowering plants}

Plant invertase inhibiters are small proteins that have been identified in a variety of plant species, such as tobacco (Greiner et al. 1998; Weil, Krausgrill et al. 1994), Arabidopsis (Link et al.2004), maize (Bate et al. 2004), tomato (Reca et al., 2008), potato (Brummell et al., 2011), and sugarcane (Shivalingamurthy et al., 2018). Wan et al. 2018, have reported that INHs, have evolved with vascular plants; our BLASTP results support this, as we did not identify any INHs from lower plants such as algae and moss (Figure 1a, b ), and inAmborella trichopoda, the common ancestor of living angiosperms (Albert et al., 2013), no INH gene was predicted, which supports the thesis that INHs evolved in flowering plants. Although the number of INH genes varies among species, INH gene duplication appears to have followed species evolution, indicating their importance in modern vascular plants. Amino acid sequence alignments of INHs from different species showed that all contained four highly conserved cysteine (Cys) residues, a hallmark of plant INHs (Rausch, \& Greiner, 2004). The nucleic acid sequences however, vary among species, even within a species (Figure 1c) .

$\mathrm{CBF}$ is a type of AP2/ERF transcription factor; it binds to CRT/DRE cis- elements in the promoter region of target genes regulating their expression. In wild-type Arabidopsis , 302 genes are induced by low temperature, in Arabidopsis constitutively expressing CBF, only 85 genes are induced by low temperature. Moreover, among genes downstream from $\mathrm{CBF}, 8$ were inhibited when $\mathrm{CBF}$ was overexpressed and these 8 genes are down-regulated by low temperature (Vogel et al., 2005). These results suggest CBF plays a key role in plant cold response. We found numerous CRT/DRE cis-elements in 5 PpINH promoters (Figure 2 ), indicating these PpINHs are targets of CBF. Expression of PpINH1 was significantly reduced in peaches during cold storage (Figure 6f ) indicatingPpINH1 is sensitive to cold stress. These data suggest that low-temperature sensitive INHs may be regulated by CBF proteins.

\subsection{PpINH1 interacts with PpVIN2, functioning as an inhibiter}

VINs regulate cell growth (Wang et al., 2010), participate in fruit sucrose metabolism (Ohyama et al., 1995; Scholes et al.1996), and act as regulators in response to stress (Rausch \& Greiner, 2004) as exemplified by the increased VIN activity in peach fruit during cold storage (He et al., 2018). Regulation of VIN by endogenous protein inhibitors occurs at both the transcriptional and translational level (Tauzin et al., 2014). In tomato, Qin et al. (2016) found that S1VIF, a tomato INH located in tomato vacuoles, mediates fruit maturation and interacts with VIN S1VI in Y2H system. As yet no studies have been conducted on the post-translational regulation of inhibitor-mediated VIN activity in peaches or other rosaceous plants. In our study, we found that in peaches only PpINH1 interacts with PpVIN2 in a Y2H screen. We also demonstrated this interaction in tobacco cells by BiFC (Figure 3 ).

Because peaches are difficult to stably transform and transgenic fruit requires 4-5 years to produce, we used the Agrobacteriumtransient transformation system to investigate biological functions of PpINH1. Our results showed that when PpINH1 is overexpressed in peach, VIN activity decreases (Figure 4e ), as would be expected if PpINH1 regulates VIN at the post-translational level. Zhang et al. (2015) also used the Agrobacterium system, introducingSly-INH tomato fruit. Sly-INH is an inhibitory protein that regulates tomato CWI activity at the post-translational level. Interestingly in our experiment, although PpINH1 expression increased substantially during cold storage, the decrease in VIN activity was not as dramatic. This disparity may be due to induction of plant defense responses by the Agrobacterium infection (Pitzschke, 2013), which would be expected to enhance VIN activity.

The interaction between PpINH1 and PpVIN2 was also shown in vitrousing recombinant proteins. The results showed that PpINH1 inhibition of PpVIN2 activity is $\mathrm{pH}$ dependent, with an optimum at $\mathrm{pH}$ 4.4, and temperature dependent, with an optimum at $35{ }^{\circ} \mathrm{C}$ (Figure $\left.5 \mathbf{i}-\mathbf{l}\right)$. It is worth noting here that most 
plant vacuoles are acidic, and the interaction between PpINH1 and PpVIN2 could be regulated via pH variations within the vacuole (Tauzin et al., 2014).

In potato, the AI StvacINV1, the INH StInvInh2B, and the sucrose non-fermentation-associated protein kinase 1 protein form a complex which regulates the activity of AI (Lin et al., 2015).Arabidopsis thaliana CWIN1 and tobacco inhibitor CIF interact to form a similar complex that has been analyzed structurally (Hothorn et al. 2010). Bioinformatics analysis indicates that PpINH1 has a four-helix bundle fold and four strictly conserved cysteine residues (Figure S3a), while PpVIN2 is predicted to contain a five-bladed betapropeller structure (Figure S3b ). As these structures are prerequisites for PpINH1and PpVIN2 to form an interaction complex (Hothorn et al. 2004ab), it is likely that PpINH1 forms a complex with PpVIN2 and mediates inhibition of PpVIN2 activity.

\subsection{Trehalose treatment affects PpINH1, leading to improved cold resistance in peaches}

In most plants, the amount of endogenous trehalose is typically low, however, it is strongly induced by environmental stresses, including extreme temperatures, salinity, and drought. Therefore, endogenous trehalose may be involved not only in plant metabolism, but also in signaling pathways (Paul et al. 2008). Application of exogenous trehalose may induce plant signal molecules that modulate the expression of stress response genes, thereby improving crops' resistance to stresses (Kosar et al. 2019). Kosar et al. (2019) have reported that the application of exogenous trehalose improves the cold resistance of crops and harvested fruits, and Ding \& Wang (2018) report that 10\% trehalose treatment enhances the cold tolerance of fresh-cut pepper fruits by enhancing antioxidant activity and reducing cell ultrastructure injury. The mechanisms of these affects however, have not yet been reported. In this study, application of $1 \%$ trehalose to peaches in cold storage resulted in significantly enhanced PPINH1 expression, reduced VIN activity, and higher sucrose content, ultimately alleviating CI symptoms (Figure 6 ). These results suggest that up-regulated INHs inhibit VIN activity at the post-translational level in peach fruit.

Like overexpression of PpINH1 inhibiting the VIN in peaches (Figure 4 ), overexpression of StInvInh2A andStInvInh2B inhibits StvacINV1 in stored tubers, alleviating cold-induced sweetening and the resulting deterioration of quality (Liu et al., 2013). Similarly, when RNAi technology was used to silence the expression of the soybean invertase inhibitor GmCIF1 in transgenic plants, CWI activity increased significantly. These results suggest that VIN activity may be negatively regulated by INHs in plants (Tang et al., 2017).

Based on our findings we suggest that upregulated the expression of PpINH1 results in the decreased VIN activity, increased sucrose content, and ultimately enhanced chilling resistance (Figure 7 ). This provides insight into the mechanism of enhancing chilling resistance by trehalose treatment.

\section{Conclusions}

In conclusion, evolutionary analysis suggests that INHs are essential for the regulation of sucrose metabolism in vascular plants, by balancing VIN activity. We demonstrated that PpINH1 interacts with PpVIN2 and inhibits VIN activity in peach fruit. Upregulation of PpINH1 expression in trehalose-treated peaches resulted in decreased VIN activity, which slowed sucrose decomposition thereby enhancing chilling resistance. Our findings provide new insight into the regulation of sucrose metabolism during chilling stress in peach fruit, and has implications for developing more effective postharvest treatment methods and breeding fruits with cold tolerant genotypes.

\section{ACKNOWLEDGEMENTS}

The research was supported by the National Key R\&D Program of China (No. 2018YFD1000200) and National Science Foundation of China (No. 31671903; 31972124).

\section{CONFLICT OF INTEREST}

Authors declare no conflicts of interest.

\section{References:}


Albert, V. A., Barbazuk, W. B., Depamphilis, C. W., Der, J. P., Leebens-Mack, J., Ma, H., .. \& Soltis, D. E. (2013). The Amborella genome and the evolution of flowering plants. Science, 342(6165) , 1241089. $10.1126 /$ science. 1241089

Bate, N. J., Niu, X., Wang, Y., Reimann, K.S., \& Helentjaris, T.G. (2004). An invertase inhibitor from maize localizes to the embryo surrounding region during early kernel development. Plant Physiology , 134(1) , 246-254. https://doi.org/10.1104/pp.103.027466

Benaroudj, N., Lee, D.H., \& Goldberg, A.L. (2001). Trehalose accumulation during cellular stress protects cells and cellular proteins from damage by oxygen radicals. Journal of biological chemistry ,276(26) , 2426124267. https://doi.org/10.1074/jbc.M101487200

Borsani, J., Budde, C.O, Porrini, L., Lauxmann, M.A., Lombardo, V.A., Murray, R., .. Lara, M.V. (2009). Carbon metabolism of peach fruit after harvest: changes in enzymes involved in organic acid and sugar level modifications. Journal of Experimental Botany ,60(6) , 1823-1837. https://doi.org/10.1093/jxb/erp055

Brummell, D.A., Chen, R.K.Y., Harris, J.C., Zhang, H., Cyril, H., Kralicek, A.V., \& Mckenzie, M.J. (2011). Induction of vacuolar invertase inhibitor mRNA in potato tubers contributes to cold-induced sweetening resistance and includes spliced hybrid mRNA variants. Journal of Experimental Botany , 62(10) , 3519-3534. https://doi.org/10.1093/jxb/err043

Castrillón-Arbeláez, P.A., \& Délano-Frier, J.P. (2011). The sweet side of inhibition: invertase inhibitors and their importance in plant development and stress responses. Current Enzyme Inhibition ,7(3) , 169-177. https://doi.org/10.2174/157340811798807588

Ding, F., Wang, R. (2018). Amelioration of postharvest chilling stress by trehalose in pepper. Scientia Horticulturae, 232 , 52-56. https://doi.org/10.1016/j.scienta.2017.12.053

Draffehn, A.M., Meller, S., Li, L., \& Gebhardt, C. (2010). Natural diversity of potato (Solanum tuberosum ) invertases. BMC Plant Biology , 10 , 271. https://doi.org/10.1186/1471-2229-10-271

Elbein, A.D., Pan, Y.T., Pastuszak, I., \& Carroll, D. (2003). New insights on trehalose: a multifunctional molecule. Glycobiology ,13(4), 17R-27R. https://doi.org/10.1093/glycob/cwg047

Glass, F., Härtel, B., Zehrmann, A., Verbitskiy, D., \& Takenaka, M. (2015). MEF13 requires MORF3 and MORF8 for RNA editing at eight targets in mitochondrial mRNAs in Arabidopsis thaliana . Molecular Plant , 8 , 1466-1477. https://doi.org/10.1016/j.molp.2015.05.008

Greiner, S., Krausgrill, S., \& Rausch, T. (1998). Cloning of a tobacco apoplasmic invertase inhibitor proof of function of the recombinant protein and expression analysis during plant development. Plant Physiology , 116(2) , 733-742. https://doi.org/10.1104/pp.116.2.733

He, X., Wei, Y., Kou, J., Xu, F., Chen, Z., \& Shao, X. (2018).PpVIN2 , an acid invertase gene family member, is sensitive to chilling temperature and affects sucrose metabolism in postharvest peach fruit. Plant Growth Regulation , 1-12 . https://doi.org/10.1007/s10725-018-0419-z

Hothorn, M., D’Angelo, I., Márquez, J.A., Greiner, S., \& Scheffzek, K. (2004a). The invertase inhibitor NtCIF from tobacco: a highly thermostable four-helix bundle with an unusual N-terminal extension. Journal of Molecular Biology , 335, 987-995. https://doi.org/10.1016/j.jmb.2003.10.066

Hothorn, M., Ende, W.V., Lammens, W., Rybin, V., \& Scheffzek, K. (2010). Structural insights into the $\mathrm{pH}$-controlled targeting of plant cell-wall invertase by a specific inhibitor protein. Proceedings of the National Academy of Sciences of the United States of America ,107(40) , 17427-17432. https://doi.org/10.1073/pnas.1004481107

Hothorn, M., Wolf, S., Aloy, P., Greiner, S., \& Scheffzek, K. (2004b). Structural insights into the target specificity of plant invertase and pectin methylesterase inhibitory proteins. Plant Cell ,16(12) , 3437-3447. https://doi.org/10.1105/tpc.104.025684 
Keunen, E., Peshev, D., Vangronsveld, J., Wim, V. D. E., \& Cuypers, A. (2013). Plant sugars are crucial players in the oxidative challenge during abiotic stress: extending the traditional concept. Plant, Cell $\mathscr{E}$ Environment ,36(7) , 1242-1255. https://doi.org/10.1111/pce.12061

Kosar, F., Akram, N.A., Sadiq, M., Al-Qurainy, F., \& Ashraf, M. (2019). Trehalose: a key organic osmolyte effectively involved in plant abiotic stress tolerance. Journal of Plant Growth Regulation , 38(2) , 606-618. https://doi.org/10.1007/s00344-018-9876-x

Lammens, W., Roy, K.L, Yuan, S., Vergauwen, R., Rabijns, A., Laere, A.V., ... Ende, W.V. (2012). Crystal structure of 6-SST/6-SFT from Pachysandra terminalis, a plant fructan biosynthesizing enzyme in complex with its acceptor substrate 6-kestose. The Plant Journal ,70 , 205-219. https://doi.org/10.1111/j.1365313X.2011.04858.x

Leebens-Mack, J.H., Barker, M.S., Carpenter, E.J., Deyholos, M.K., Gitzendanner, M.A., Graham, S.W., ... Wong, G.K.S. (2019). One thousand plant transcriptomes and the phylogenomics of green plants. Nature . 574, 679-685 https://doi.org/10.1038/s41586-019-1693-2

Li, X., Xu, Y., Shen, S., Yin, X., Klee, H., Zhang, B., \& Chen, K. (2017). Transcription factor CitERF71 activates the terpene synthase gene CitTPS16 involved in the synthesis of E-geraniol in sweet orange fruit. Journal of Experimental Botany . 68(17) , 4929-4938. https://doi.org/10.1093/jxb/erx316

Lin, Y., Liu, J., Liu, X., Ou, Y., Li, M., Zhang, H., Song, B., \& Xie, C. (2013). Interaction proteins of invertase and invertase inhibitor in cold-stored potato tubers suggested a protein complex underlying post-translational regulation of invertase. Plant Physiology and Biochemistry , 73 , 237-244. https://doi.org/10.1016/j.plaphy.2013.09.012

Lin, Y., Liu, T., Liu, J., Liu, X., Ou, Y., Zhang, H., .. \& \& Xie, C. (2015). Subtle regulation of potato acid invertase activity by a protein complex of invertase, invertase inhibitor, and sucrose nonfermenting1-related protein kinase. Plant Physiology ,168 , 1807-1819. https://doi.org/10.1104/pp.15.00664

Link, M., Rausch, T., \& Greiner, S. (2004). In Arabidopsis thaliana, the invertase inhibitors AtC/VIF1 and 2 exhibit distinct target enzyme specificities and expression profiles. FEBS Letters , 573 , 105-109. https://doi.org/10.1016/j.febslet.2004.07.062

Liu, X., Lin, Y., Liu, J., Song, B., Ou, Y., Zhang, H., Li, M., \& Xie, C. (2013). StInvInh2 as an inhibitor of StvacINV1 regulates the cold-induced sweetening of potato tubers by specifically capping vacuolar invertase activity. Plant Biotechnology Journal ,11 , 640-647. https://doi.org/10.1111/pbi.12054

Liu, X., Song, B., Zhang, H., Li, X.Q., Xie, C., \& Liu, J. (2010). Cloning and molecular characterization of putative invertase inhibitor genes and their possible contributions to cold-induced sweetening of potato tubers. Molecular Genetics and Genomics , 284, 147-159. https://doi.org/10.1007/s00438-010-0554-3

Liu, X., Zhang, C., Ou, Y., Lin, Y., Song, B., Xie, C., Liu, J., \& Li, X.Q. (2011). Systematic analysis of potato acid invertase genes reveals that a cold-responsive member, StvacINV1, regulates cold-induced sweetening of tubers. Molecular Genetics and Genomics ,286 , 109-118. https://doi.org/10.1007/s00438-011-0632-1

Lurie, S., \& Crisosto C.H. (2005). Chilling injury in peach and nectarine. Postharvest Biology and Technology , 37, 195-208. https://doi.org/10.1016/j.postharvbio.2005.04.012

Ohyama, A., Ito, H., Sato, T., Nishimura, S., Imai, T., \& Hirai, M. (1995). Suppression of acid invertase activity by antisense RNA modifies the sugar composition of tomato fruit. Plant and Cell Physiology ,36 , 369-376. https://doi.org/10.1093/oxfordjournals.pcp.a078769

Ou, Y., Song, B., Liu, X., Lin, Y., Zhang, H., Li, M., Fang, H., \& Liu, J. (2013). Profiling of StvacINV1 expression in relation to acid invertase activity and sugar accumulation in potato cold-stored tubers. Potato Research , 56 , 157-165. https://doi.org/10.1007/s11540-013-9237-x 
Paul, M.J., Primavesi, L.F., Jhurreea, D., \&Zhang, Y. (2008). Trehalose Metabolism and Signaling. Annual Review of Plant Biology ,59(1) , 417-441. https://doi.org/10.1146/annurev.arplant.59.032607.092945

Pitzschke, A. (2013). Agrobacterium infection and plant defense-transformation success hangs by a thread. Frontiers in Plant Science , 4 , 1-12. https://doi.org/10.3389/fpls.2013.00519

Puig, C.P., Dagar, A., Ibanez, C.M., Singh, V., Crisosto, C.H., Friedman, H., Lurie, S., \& Granell, A. (2015). Pre-symptomatic transcriptome changes during cold storage of chilling sensitive and resistant peach cultivars to elucidate chilling injury mechanisms.BMC Genomics , 16(245), 1-35. https://doi.org/10.1186/s12864015-1395-6

Qin, G., Zhu, Z., Wang, W., Cai, J., Chen, Y., Li, L., \& Tian, S. (2016). A tomato vacuolar invertase inhibitor mediates sucrose metabolism and influences fruit ripening. Plant Physiology ,172(3), 1596-1611. https://doi.org/10.1104/pp.16.01269

Rausch, T., \& Greiner, S. (2004). Plant protein inhibitors of invertases. Biochimica et Biophysica Acta, 1696 , 253-261. https://doi.org/10.1016/j.bbapap.2003.09.017

Reca, I.B., Brutus, A., D’Avino, R., Villard, C., Bellincampi, D., \& Giardina, T. (2008). Molecular cloning, expression and characterization of a novel apoplastic invertase inhibitor from tomato (Solanum lycopersicum ) and its use to purify a vacuolar invertase.Biochimie , 90 , 1611-1623. https://doi.org/10.1016/j.biochi.2008.04.019

Schaffer, A.A., Rylski, I., \& Fogelman, M. (1989). Carbohydrate content and sucrose metabolism in developing Solanum muricatum fruits.Phytochemistry , 28(3) , 737-739. https://doi.org/10.1016/00319422(89)80105-0

Scholes, J., Bundock, N., Wilde, R., \& Rolfe, S. (1996). The impact of reduced vacuolar invertase activity on the photosynthetic and carbohydrate metabolism of tomato. Planta , 200 , 265-272. https://doi.org/10.1007/BF00208317

Schwimmer, S., Makower, R.U., \& Rorem, E.S. (1961). Invertase \& invertase inhibitor in potato. Plant Physiology , 36 , 313. http://doi.org/10.1104/pp.36.3.313

Shao, X., Zhu, Y., Cao, S., Wang, H., \& Song, Y. (2012). Soluble sugar content and metabolism as related to the heat-induced chilling tolerance of loquat fruit during cold storage. Food and Bioprocess Technology, 6(12) , 3490-3498. https://doi.org/10.1007/s11947-012-1011-6

Shivalingamurthy, S.G., Anangi, R., Kalaipandian, S., Glassop, D., King, G.F., \& Rae, A.L. (2018). Identification and functional characterization of sugarcane invertase inhibitor (ShINH1 ): A potential candidate for reducing pre- and post-harvest loss of sucrose in sugarcane. Frontiers in Plant Science , 9 , 1-14. https://doi.org/10.3389/fpls.2018.00598

Tang, X., Tao, S., Han, M., Wei, L., Wang, W., Yu, Z., ... Liu, L. (2017). Suppression of extracellular invertase inhibitor gene expression improves seed weight in soybean (Glycine max). Journal of Experimental Botany , 68(3) , 469-482. https://doi.org/10.1093/jxb/erw425

Tauzin, A.S., Sulzenbacher, G., Lafond, M., Desseaux, V., Reca, I.B., Perrier, J., .. Giardina, T. (2014). Functional characterization of a vacuolar invertase from Solanum lycopersicum : posttranslational regulation by N-glycosylation and a proteinaceous inhibitor. Biochimie , 101 , 39-49. https://doi.org/10.1016/j.biochi.2013.12.013

Vogel, J. T., Zarka, D. G., Van Buskirk, H. A., Fowler, S. G., \& Thomashow, M. F. (2005). Roles of the CBF2 and ZAT12 transcription factors in configuring the low temperature transcriptome of Arabidopsis . The Plant Journal, 41(2), 195-211 • 10.1111/j.1365-313X.2004.02288.x

Wan, H., Wu, L., Yang, Y., Zhou, G., \& Ruan, Y. L. (2018). Evolution of Sucrose Metabolism: The Dichotomy of Invertases and Beyond. Trends in Plant Science , 23(2) ,163-177. 
https://doi.org/10.1016/j.tplants.2017.11.001

Wang, K., Shao, X., Gong, Y., Zhu, Y., Wang, H., Zhang, X., .. Lu, H. (2013). The metabolism of soluble carbohydrates related to chilling injury in peach fruit exposed to cold stress. Postharvest Biology and Technology , 86 , 53-61. https://doi.org/10.1016/j.postharvbio.2013.06.020

Wang, L., Li, X.R., Lian, H., Ni, D.A., He, Y.K., Chen, X.Y., \& Ruan, Y.L. (2010). Evidence that high activity of vacuolar invertase is required for cotton fiber and Arabidopsis root elongation through osmotic dependent and independent pathways, respectively. Plant Physiology, 154, 744-756. https://doi.org/10.1104/pp.110.162487

Weil, M., Krausgrill, S., Schuster, A., \& Rausch, T. (1994). A 17-kDaNicotiana tabacum cell-wall peptide acts as an in-vitro inhibitor of the cell-wall isoform of acid invertase. Planta , 193 , 438-445. https://doi.org/10.1007/BF00201824

Yu, L., Liu, H., Shao, X., Yu, F., Wei, Y., Ni, Z., Xu, F., \& Wang, H. (2016). Effects of hot air and methyl jasmonate treatment on the metabolism of soluble sugars in peach fruit during cold storage.Postharvest Biology and Technology , 113 , 8-16. http:// doi.org/10.1016/j.postharvbio.2015.10.013

Zhang, N., Jiang, J., Yang, Y., \& Wang, Z. (2015). Functional characterization of an invertase inhibitor gene involved in sucrose metabolism in tomato fruit. Journal of Zhejiang University Science B , 16(10), 845-856. https://doi.org/10.1631/jzus.B1400319

Zhang, Y.L., Zhang, A.H., \& Jiang, J. (2013). Gene expression patterns of invertase gene families and modulation of the inhibitor gene in tomato sucrose metabolism. Genetics and Molecular Research ,12(3), 3412-3420. http://doi.org/10.4238/2013.January.24.1

\section{Figure legends}

Figure 1. INH evolution in green plants. (a ) Phylogenetic tree constructed using INH proteins from 100 representative green plant species. (b ) INH gene copy number in 45 flowering plant species. (c ) Conservation of INH genes in 45 plants. Codons that encode the four highly conserved cysteine residues are shown in boxes, and the height of the logo indicates residue frequency.

Figure 2. Promoter analysis of PpINHs. Promoter regions are $3000 \mathrm{bp}$ in length directly upstream from the first codon. Putative CBF/DREB (C-repeat binding factor/dehydration responsive element) binding sites are indicated by arrowheads.

Figure 3. Interaction analysis of PpVIN2 and PpINH1-5 in vivo . (a ) Interaction of five PpINH proteins and PpVIN2 analyzed using the Y2H system. The yeast strain was co-transformed with PpVIN2-pGBKT7 (BD) and PpINHx-pGADT7 (AD). BD-p53 and AD-T were used as positive controls, while BD-Lam and AD-T were used as negative controls. Yeast cells were spotted onto solid media (composition shown on left) and then incubated at $30 \mathrm{degC}$ for $72 \mathrm{~h}$. Columns A-E correspond to cells expressing PpINH1, 2, 3, 4, and 5, respectively. Interaction is detected only in column A (PpINH1). (b ) Subcellular localization was visualized for both proteins in tobacco leaves. The empty vector served as a negative control. Scale bars represent $10 \mu \mathrm{m}$ to $20 \mu \mathrm{m}$. (c ) BiFC analysis of the interaction between PpINH1 and PpVIN2 in tobacco epidermal cells. Combinations of PpVIN2 - YN with YC,PpINH1 - YC with YN, and YN with YC served as negative controls. YC, C-termini of YFP; YN, N-termini of YFP. Scale bars represent $25 \mu \mathrm{m}$ to $75 \mu \mathrm{m}$.

Figure 4. Overexpression (OE) of PpINH1 inhibits VIN activity in vivo . Peach fruit in the green ripening stage are shown at $0 \mathrm{~h}(\mathbf{a})$ and $36 \mathrm{~h}(\mathbf{b})$ after injection withAgrobacterium to obtain transient expression of PpINH1 . (c ) Histochemical GUS staining of peach tissue from fruits injected with pBI121-PpINH1 -GV3101 or pBI121-GV3101. Images were obtained $36 \mathrm{~h}$ after injection. Samples were photographed separately and the images were combined to create a collage. (d ande ) Effects of transiently overexpressed PpINH1 on the expression of PpINH1 (d ) and VIN activity (e ) in peach at 0, 24, 36, 48, and $72 \mathrm{~h}$ after injection with Agrobacterium . Values are means $\pm \mathrm{SE}, \mathrm{n}=3$. Student'st -test was used to assess differences between 
treatment and control. "*", “**", and “***" indicate significant differences at p i 0.05, 0.01, and 0.001 , respectively.

Figure 5.Expression, identification, and purification of PpINH1and PpVIN2 protein, and their interaction in vitro. SDS-PAGE (a ) and western blot analysis (b ) of PpINH1 detected in BL21(DE3) cell fractions. SDS-PAGE (c ) and western blot analysis (d ) of purified PpINH1. SDS-PAGE (e ) and western blot analysis (f ) of PpVIN2 expressed in X-33 cells. SDS-PAGE ( $\mathbf{g}$ ) and western blot analysis (h ) of purified PpVIN2. Arrows indicate the position of the recombinant protein. (i ) Effect of PpINH1 on PpVIN2 activity at different $\mathrm{pH}$ levels. (j ) Effect of PpINH1 on PpVIN2 at different $\mathrm{pH}$ levels, expressed as inhibition rate (\%). (k ) Effect of PpINH1 on PpVIN2 activity at different temperatures. (1 ) Effect of PpINH1 on PpVIN2 at different temperatures, expressed as inhibition rate (\%).

Figure 6. Effect of trehalose treatment on postharvest peach fruits. (a ) Representative images of CI in treated and untreated peaches after storage for 21 and 28 days at $5 \operatorname{degC}$. (b ) CI index, (c ) sucrose content, (d ) VIN activity, (e ) P p VIN2 expression, and (f ) PpINH1 expression, in trehalose-treated and untreated peaches during cold storage. Values are means +- SE. Student's $t$-test was used to assess differences between treatment and control groups. "**, “*”, "***, and "***" indicate significant differences at p i $0.05,0.01$, and 0.001 , respectively.

Figure 7. A proposed model for inhibition of VIN activity by PpINH1. Upper panel: During cold storage, PpVIN2 expression and VIN activity both increase. VIN decomposes sucrose, a sugar that helps prevent chilling injury. Lower panel: PpINH1 inhibits VIN activity at the post-translational level. Trehalose treatment increases PpINH1 expression and thus indirectly increases sucrose levels, protecting against chilling injury. 
(a)

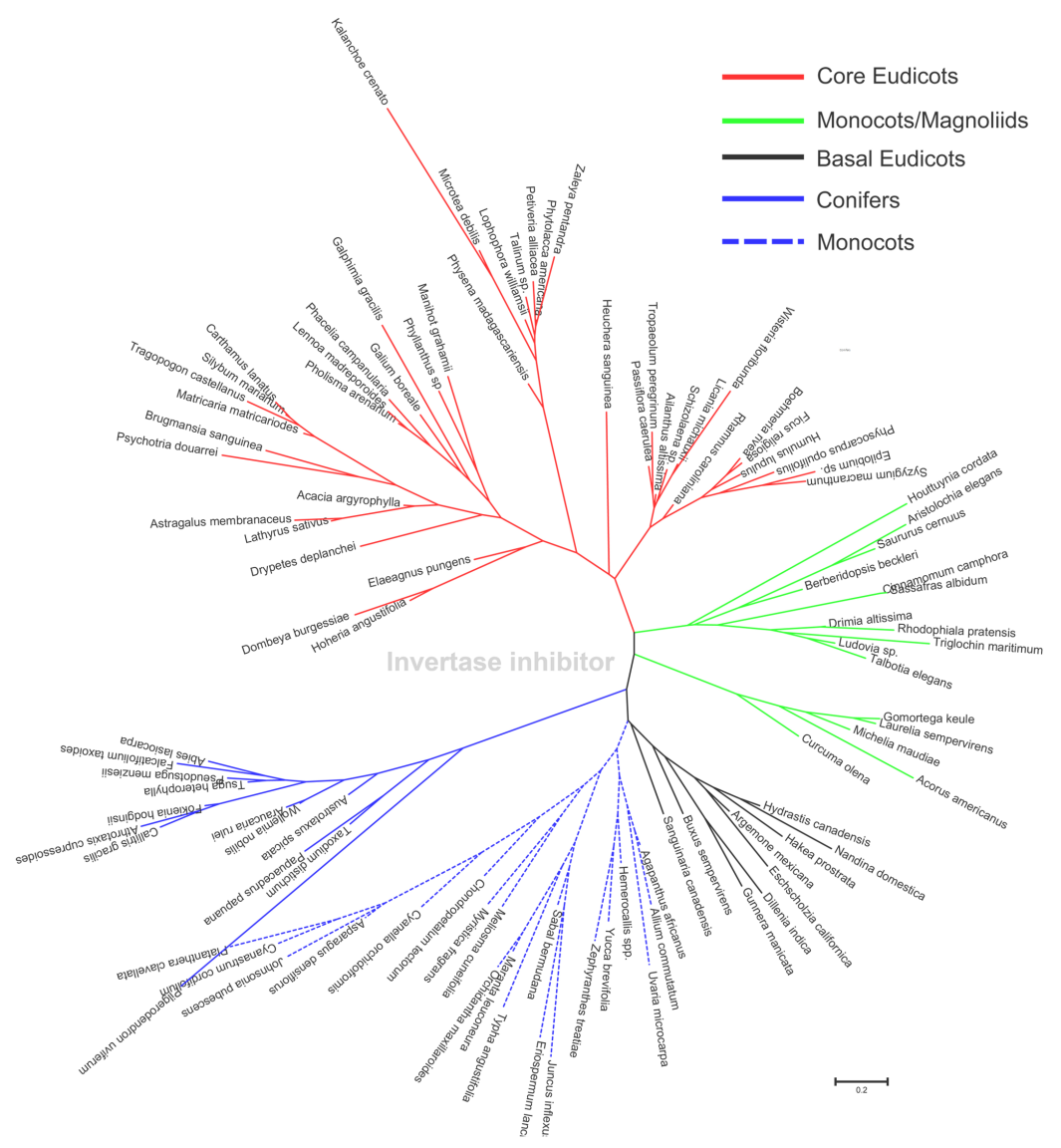

(b)

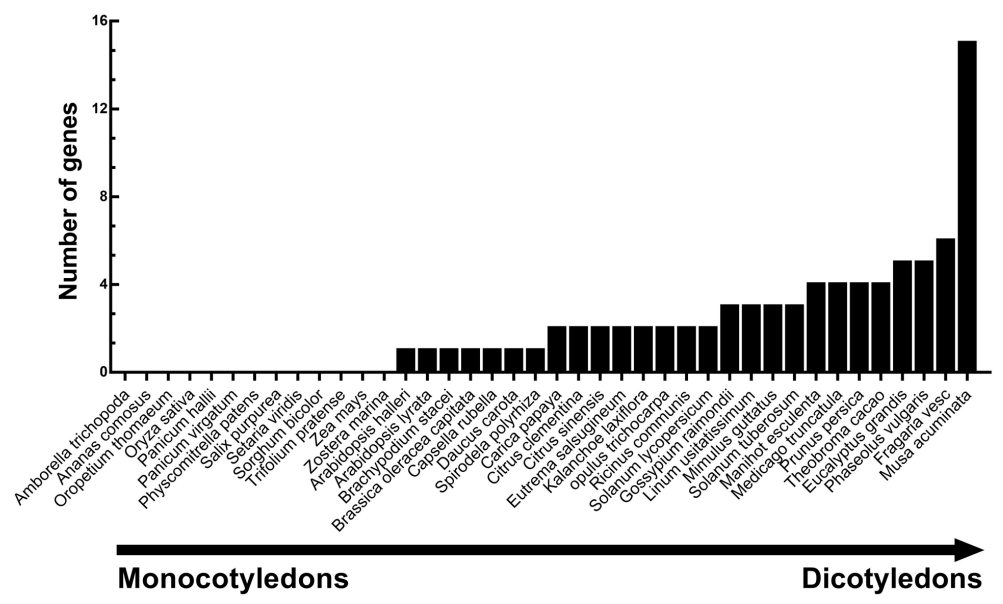

(c)

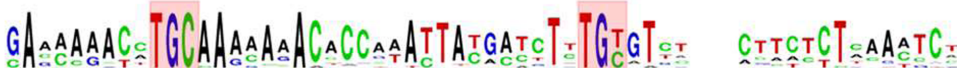

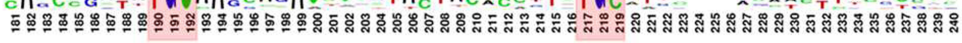

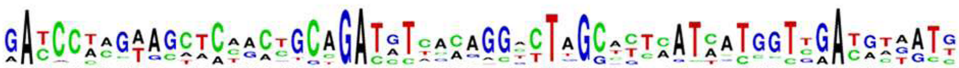

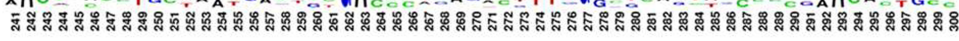

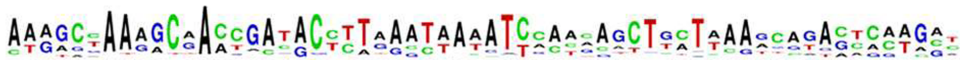

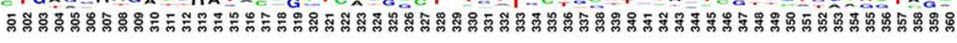

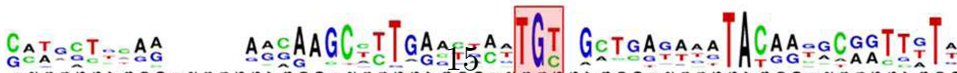

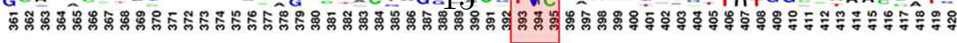

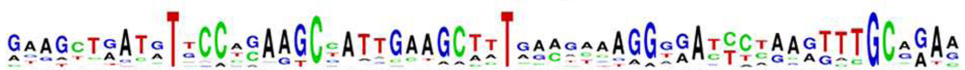

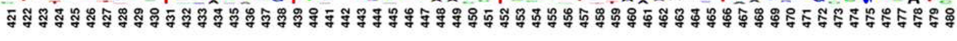

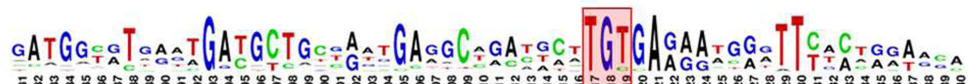




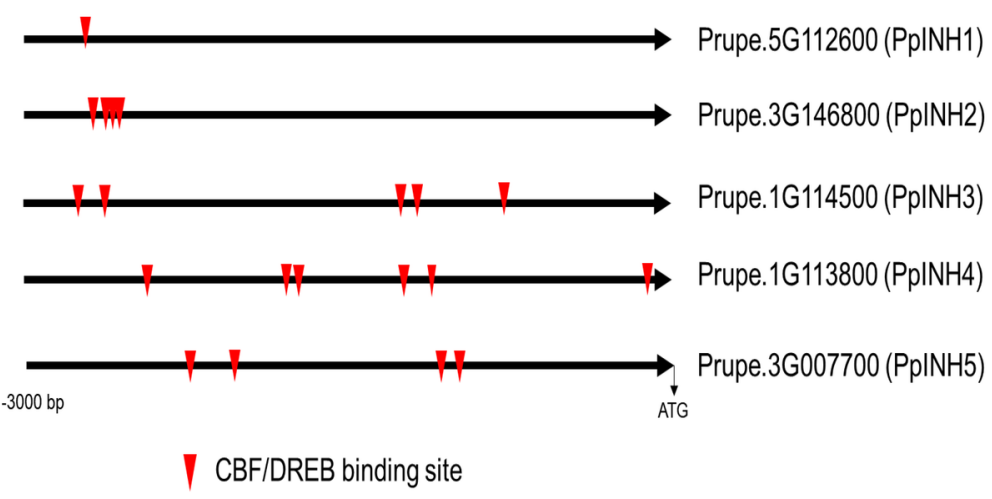


(a) BD-53+AD-T BD-Lam+AD-T A

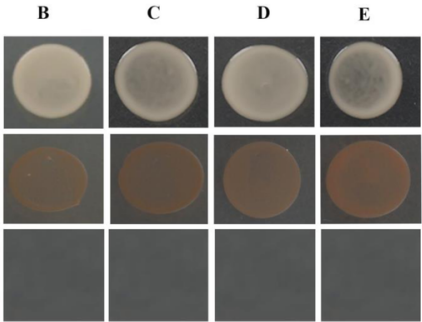

(b)
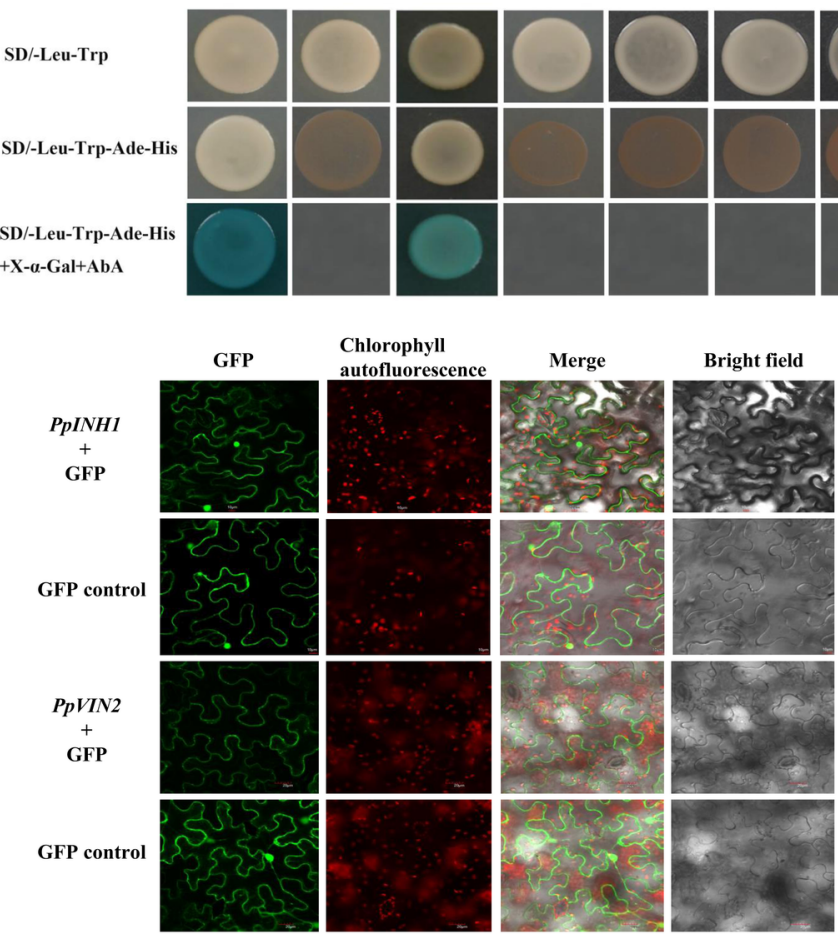

(c)

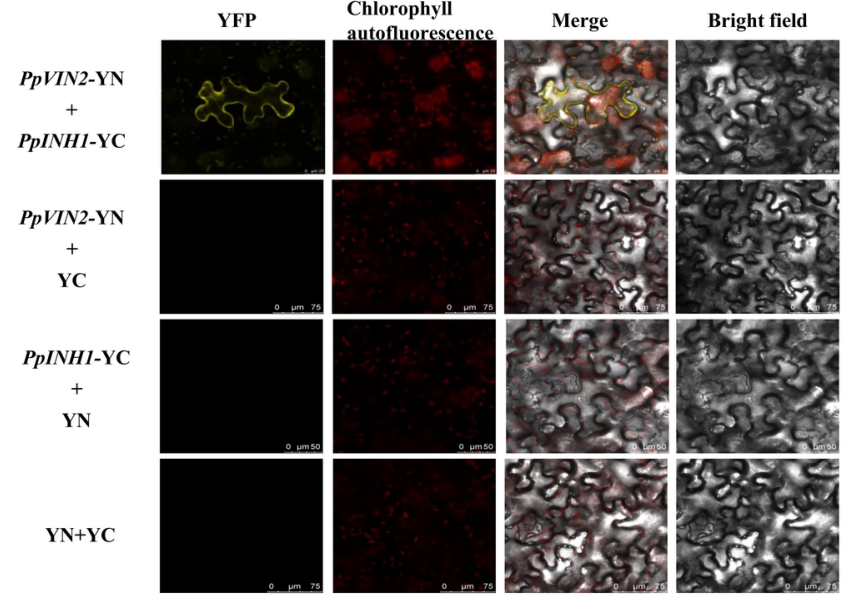


(a)

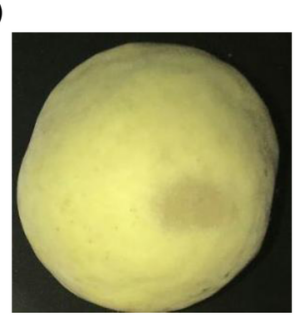

(b)

(d)

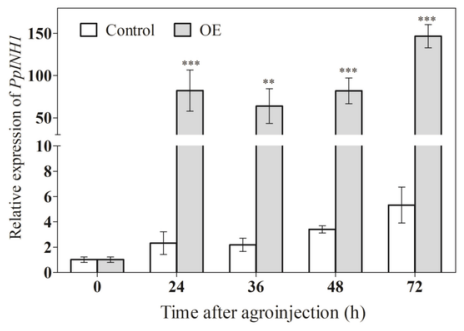

(c)
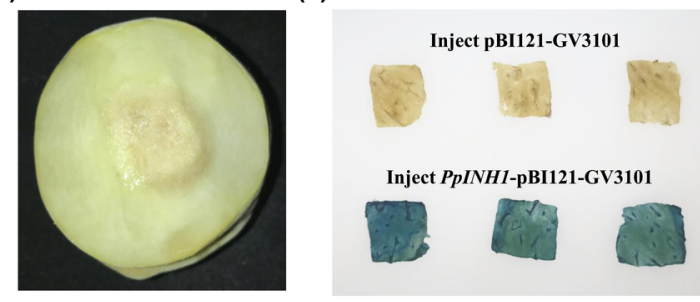

(e)

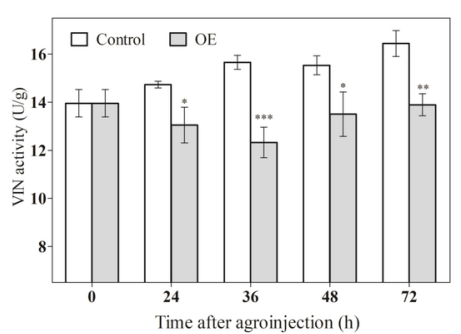



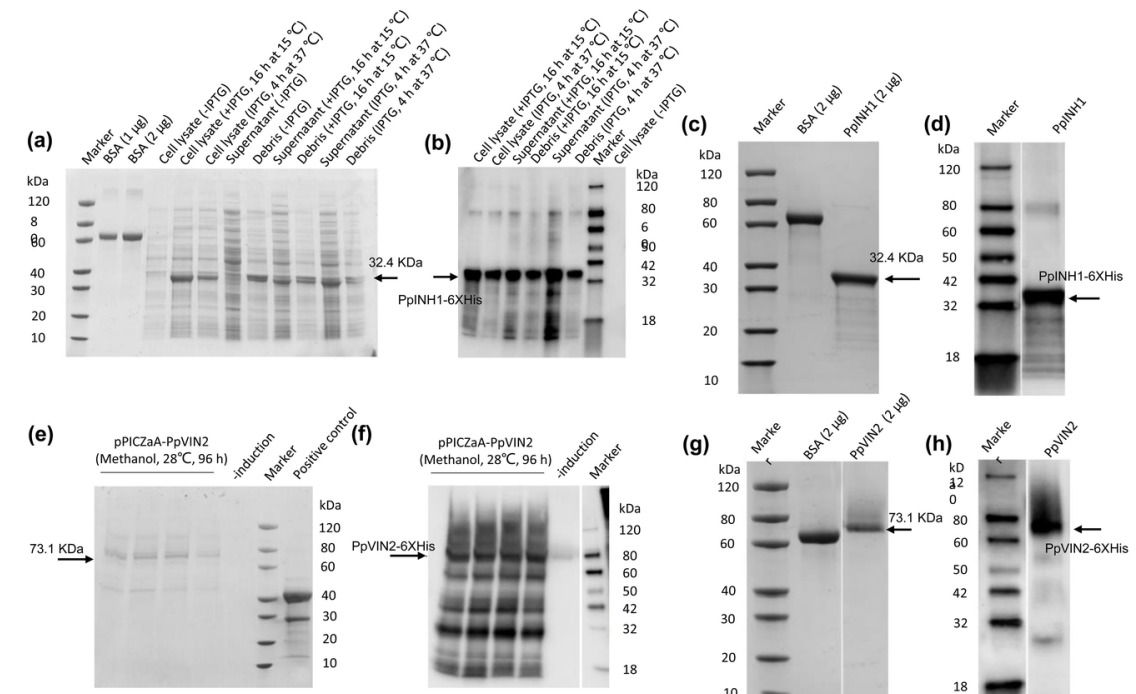

(i)

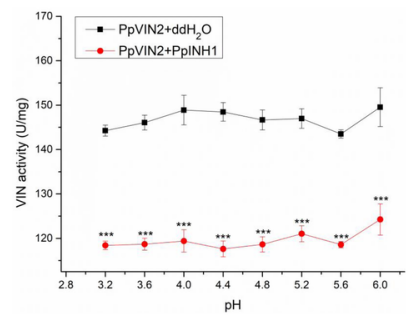

(k)

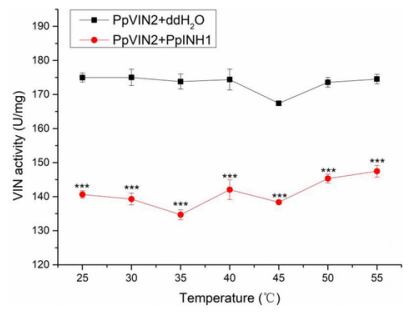

(j)

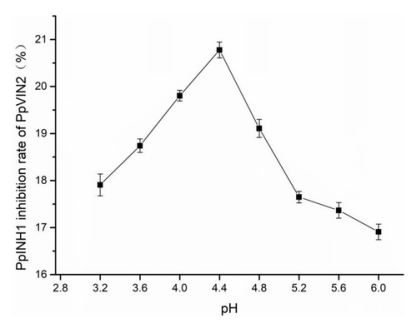

(I)

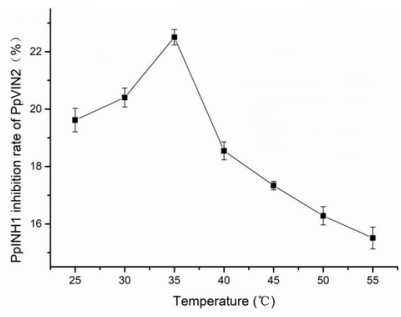


(a)

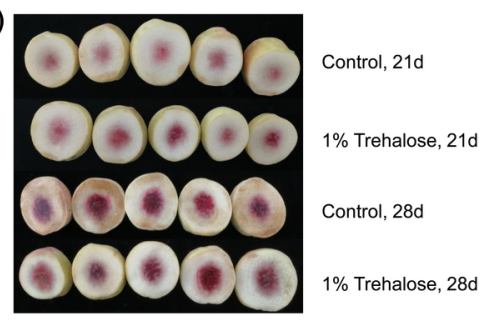

(c)

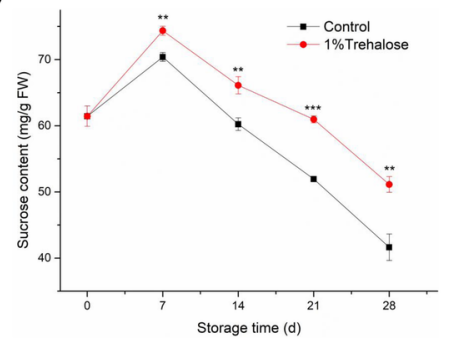

(e)

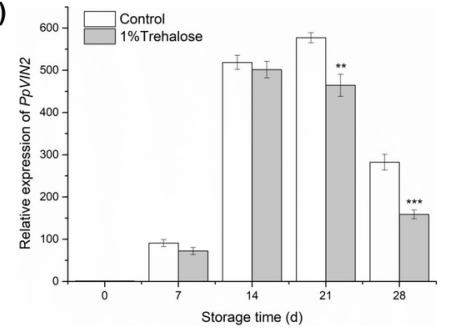

(b)

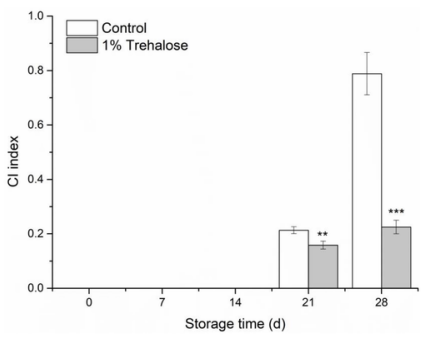

(d)

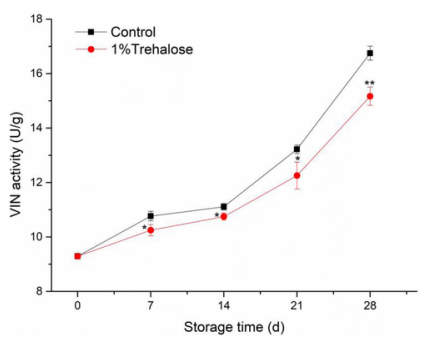

(f)

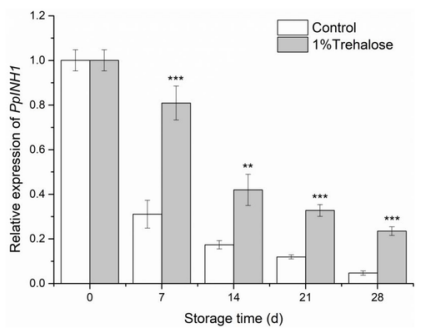

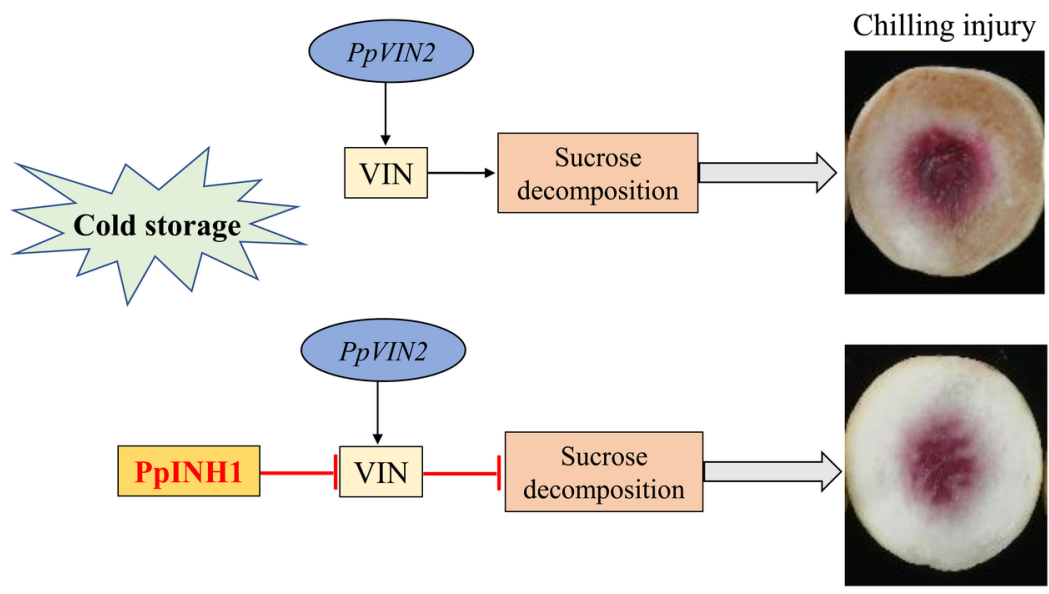

Chilling resistance 